\title{
Julian ,Apostata' und die philosophische Reaktion gegen das Christentum
}

\author{
Die „Pseudomorphosen“ des platonischen Denkens \\ im „magischen Zeitalter“"
}

Christian Schäfer

Das Naheliegende ist das Erstaunliche. Nicht die differentia specifica die ist jedem früher oder später auffällig -, sondern die Erkenntnis des genus proximum macht heute $\mathrm{zu}-$ meist die Kunst des Unterscheidens aus und ermöglicht die Definitionen.

Jorge Luis Borges

\section{Die Problemstellung}

Es scheint so, als hätte man sich daran gewöhnt, im Versuch der philosophischen Reaktion gegen das Christentum, wie er unter Kaiser Julian unternommen wurde, ein Kuriosum zu sehen, das gerade auch deswegen als „spannend“ gilt, weil hier der Deutungsfolklore nach der Lauf der Dinge einen Zuspätgekommenen mit recht unchristlicher Erbarmungslosigkeit abgestraft hat. Das vermeintlich Resultative der Geschichte lässt den Betrachter dabei allzu gerne fasziniert oder kopfschüttelnd feststellen: „Er dachte offenbar wirklich, man könne ... - heute aber wissen wir doch, dass ...“. Vielleicht hat Henning Ottmann diese standardisierte Ansicht in neuester Zeit am bündigsten ausgesprochen:

Das große Projekt des Kaisers, die religionspolitische Rückwendung zum Heidentum, war zum Scheitern verurteilt. In der Asche war nicht mehr ausreichend Glut. Mit philosophischem Synkretismus und Neuplatonismus waren die Massen nicht zu erreichen. Was Julian versuchte, war vergeblich. Er verschrieb sich einer Vergangenheit, die selbst in seiner eigenen Wahrnehmung nicht mehr als das erschien, was sie einmal gewesen war. Das mag man wie David Friedrich Strauß romantisch nennen, und im 
Gegensatz zu Strauß muß man an der subjektiven Ehrlichkeit dieses Träumers nicht zweifeln. Aber ein Träumer und Schwärmer ist er gewesen. Er wußte nicht, was er tat.

Julian genießt dementsprechend bei den Interpreten die Sympathien oder erregt das Mitleid eines Don Quijote - oder meistens beides gleichermaßen. Gerade das mit tiefster Überzeugung angegangene Aussichtlose im Verkennen der Zeichen der Zeit, das unbeirrt Akairotische, macht das Faszinosum von Julians Überzeugungen und Unternehmen offenbar zum guten Teil aus. ${ }^{2}$

Dabei ist das doch gerade, was das „Spannende“ oder das Kuriose betrifft, als Deutungsannahme eigentlich eher erstaunlich. Denn die Tatsache, dass hier jemand an prominenter Stelle im vierten Jahrhundert mächtig gegen die geistige Ausbreitung und Selbstgewissheit des Christentums rebelliert und mit den Waffen der geistigen und politischen Auseinandersetzung zur Wehr setzt, könnte man doch genauso gut als eher vorhersehbar oder - soweit das keine contradictio in adiecto ist - als ,psychologisch folgerichtig“ betrachten. Der Grund dafür, dass Julian Apostata in den Augen vieler als ein seltsames und verloren romantisches Phänomen betrachtet wird, ${ }^{3}$ das sich offenbar gegen den Lauf der Zeit stemmt

1 Ottmann, Henning, Geschichte des politischen Denkens, Band 2/1: Die Römer, Stuttgart 2002, S. 354 .

2 Faszinierend und spannend auch unter dem falsch vergleichenden Gesichtspunkt des Musters fürs Eigene, wenn nach langem Usus der Interpreten anhand des vierten Jahrhunderts die eigene Gegenwart diagnostiziert wird. Es ist eine spätestens seit der Renaissance eingeübte Gewöhnung, die Antike zur Musterkultur der eigenen oder sogar nachgerade zum Paradigma jeder Geschichtsentwicklung zu machen. Dadurch, dass die ersten Jahrhunderte nach Christus gemäß einer verschwommenen Vorstellung von „Spätantike“ dieser Musterantike zugeschlagen werden, liegen die vermeintlichen Spiegelbildlichkeiten der wie selbstverständlich distanziert analysierten Gegenwart zu diesem Muster einer Spätzivilisation blank. Was Julian betrifft, sind das unter anderem: Das vermutete Wiederaufblühen von wundergläubiger Irrationalität und Okkultismus, ein überspanntes Anhängen an Erlösungslehren aus dem Orient, der Rückzug in private Innerlichkeit, etc. (für ein typisches Beispiel vgl. die nächste Anmerkung 3 zu Strauß). Zur Problematizität dieser und ähnlicher Auffassungen und ihres Ursprungs vgl. Demandt, Alexander, Der Untergang Roms als Menetekel, in: Ders., Geschichte der Geschichte, Köln 1997, S. 39-59; Ders., Spengler und die Spätantike, in: Ders., Geschichte der Geschichte, S. 60-80; sowie Ders., Der Fall Roms. Die Auflösung des Römischen Reichs im Urteil der Nachwelt, München 1984, insbesondere S. 494ff. Über das intrikate Verhältnis von Moderne und „Spätantike“ siehe unter anderem Schmitt, Arbogast, Die Moderne und Platon, Stuttgart 2003, S. 66-77, 207-215 und öfter. Dass gerade die vermutete „religiöse Erneuerung“ mit dem diagnostizierten politischen oder kulturellen Abstieg korreliert, die „Angst vor dem Ende“ mit dem „Ende der Angst“ und die „Abendgefühle des Weltentages“ mit den „Morgengefühlen des Weltensabbats“, zeigt wiederum Demandt, Alexander, Historische Apokalyptik, in: Ders., Der Fall Spengler. Eine kritische Bilanz, Köln/Weimar/Wien 1994, S. 21-44, insbesondere S. $25 f$.

3 So der Tenor des Werks von Strauß, David Friedrich, Der Romantiker auf dem Throne der Caesaren oder Julian der Abtrünnige, Mannheim 1847. Entsprechend finden sich bei Strauß dann auch gleichermaßen die üblichen Fortschrittskritiken an der „Spätantike“: Das, was bei Julian als ,alt“" gelten wollte, ist in Wirklichkeit „spät“, synkretistisch, mystisch versponnen, neu ohne es sein zu wollen, und so weiter. Kurz: „Romantik, ob bei Julian oder in seiner eigenen 
und eigentlich von Anfang an zum Scheitern verurteilt war, muss jedenfalls erst auf seine Sachhaltigkeit geprüft werden. - Und auf die sachliche Richtigkeit der Voraussetzungen solch einer Überprüfung. Denn es ist ja nicht so, dass, wie es im 19. Jahrhundert ein prominenter Historiker formuliert hat, die gestalt- und zielgebende Bestimmung und eigentliche Leistung der paganen hellenischen Welt darin bestanden hätte, sich selbst vollkommen zu überwinden und obsolet $\mathrm{zu}$ machen, damit der weltgeschichtliche Auftritt des Christentums erfolgen konnte. ${ }^{4}$ Und dennoch ist das anscheinend - in ,,politisch korrekt" säkularisierter Form - die zumindest stillschweigende Annahme geblieben, über alle Sympathien oder Antipathien dem Phänomen des Auftretens des Christentums gegenüber hinweg: Dass zu diesen Zeiten etwas Neues, nämlich Christliches, in der historischen Stufenfolge nachrückt und das Gewesene geradezu folgerichtig verdrängt, übersteigt und in einer eindeutig sinngerichteten zeitlichen Evolution ,aufhebt“". Es bleibt die Frage, wieviel Hegel (der steht ja bei diesen und ähnlichen Entwürfen im Hintergrund $^{5}$ ) die Geschichte eigentlich zu vertragen imstande ist ${ }^{6}$ und ob denn (einmal aus theologischer Warte betrachtet) wirklich das mit der „Fülle der Zeit“ gemeint sein kann. Die Gegenfrage müsste daher vielleicht eher lauten: Erscheint es denn nicht vielmehr als gewissermaßen zu erwarten, dass es während der nur etwas mehr als siebzig Jahre, die zwischen der ersten offiziellen Anerkennung des Christentums im Römischen Reich durch Constantin den Großen und der Erhebung des Christentums zur Reichsreligion durch Theodosius liegen, dazu kom-

Gegenwart, war für Strauß innere Unwahrheit, ein sich selbst die Wahrheit verbergender Mystizismus" (Ottmann (Anm. 1), S. 348).

4 Droysen, Johann Gustav, Geschichte des Hellenismus, Hg. E. Bayer, Tübingen 1952, Teil III, S. 6-9 und S. $17 f$.

5 Die Hegelschen Grundlagen dafür finden sich bei Droysen des Öfteren angesprochen, so zum Beispiel in folgender Passage aus der Geschichte des Hellenismus (Anm. 4), Teil I, S. 198: „In solchen Siegen vollzieht sich die Kritik dessen, was bisher war und galt, aber nicht weiterführt, mächtig und selbstgewiss schien, aber in sich krank und brüchig ist. Nicht das Herkommen noch das ererbte Recht, nicht Friedlichkeit noch Tugend noch sonstiger persönlicher Wert schützt dann vor der überwältigenden Macht dessen, dem das Verhängnis geschichtlicher Größe zuteil geworden ist“. Vgl. dazu auch Bravo, Benedetto, Hégélianisme et recherche historique dans l'oeuvre de J.G. Droysen. Antiquitas Graeco-Romana, Prag 1968, S. 151ff.; sowie Christ, Karl, Johann Gustav Droysen, in: Ders., Von Gibbon zu Rostovtzeff. Leben und Werk führender Althistoriker der Neuzeit, Darmstadt 1972, S. 50-67, vor allem S. 52 und S. 66.

6 Von früh an hatte Hegel dabei gerade die ,wunderbare Revolution“ der „Ablösung“ der Antike durch das Christentum als eine der Hauptaufgaben der ,denkenden Geschichtsforscher“ angesehen: Vgl. Hegel, W.G.F., Theologische Jugendschriften, Hg. H. Nohl, Tübingen 1907, S. 220. Im Gefolge Hegels hatten auch Ernst Curtius und Jakob Burckhardt ein aszendentes Aufhebungsmuster im Verhältnis von müde und zweifelnd gewordener Antike und jugendlich selbstgewissem Christentum gesehen. So lautet beispielsweise Burckhardts Bestandsaufnahme der Zeit Kaiser Constantins: „Eine hohe geschichtliche Notwendigkeit hatte das Christentum auf Erden eingeführt, als Abschluß der antiken Welt, als Bruch mit ihr, und doch zu ihrer teilweisen Rettung und Übertragung auf die neuen Völker" (Jakob Burckhardt, Werke Band 2. JakobBurckhardt-Gesamtausgabe, Hg. E. Dürr, Basel 1929, S. 113). 
men würde, dass gegen diese Entwicklung auch aufbegehrt und mit Macht ein anderer Weg gesucht werden würde?

\section{2. „Übergangszeit“ und „Pseudomorphose“}

Eine allzu naive aszendenztheoretische Betrachtung der Dinge mag vielleicht auch daran hängen, dass man den Konflikt zwischen Julian und dem Christentum allzu sehr wie eine querelle des anciennes et des modernes anzusehen gewohnt ist. Diese Ansicht ist aber falsch und meist doch nur eine Umdeutung späterer Kontroversen auf auch in diesem Sinne längst vergangene Zeiten. Eine Ansicht übrigens, die auch nicht dadurch zur Tatsache geadelt wird, dass Julian, Symmachus und andere pagane Vordenker im vierten Jahrhundert die Anciennität ihrer Sache wiederholt ins Feld führen: Es war für sie eher eine Anamnesis des Ewigkeitsanspruchs ihrer Überzeugungen, als ein nostalgisches Argument. ${ }^{7}$ - Selbst wenn diese Überzeugungen ein Auf und $\mathrm{Ab}$ in der Geschichte zeigten und $\mathrm{zu}$ anderen Zeiten kräftiger geblüht oder ihre Aristien gehabt hatten. ${ }^{8}$

Auch wird es kaum helfen, die hier zur Frage stehende Epoche kurzerhand als „Übergangszeit“ zu etikettieren und dafür generell „Dekadenz-““ und „Krisenphänomene" diagnostizieren zu wollen, wie sie eben vermeintlicherweise zu Selbstfindungsphasen und „dark ages“ gehören. Bedenkenswert ist im Gegensatz zu solchen Vermutungen die folgende Aussage von José Ortega y Gasset, die eine Existenz historischer „Übergangsphasen“ zwar nicht in Abrede stellt, aber ganz richtig davor warnt, diese „Phasen“ allein vom Übergang her zu definieren:

Wenn wir von Übergang und Dekadenz sprechen, müssen wir uns darüber Rechenschaft geben, wie wenig wir damit sagen; statt mit diesen Begriffen wie mit Mechanismen zu manipulieren, die uns durch ihr eigenes automatisches Wirken ein Stück der Vergangenheit aufzuklären vorgeben, sollten wir darin eine Aufforderung sehen, die seltsame und konkrete Gestalt zu erforschen, die das menschliche Leben unter den abstrakten Bezeichnungen ,Übergang' und ,Dekadenz' annimmt. ${ }^{9}$

Was die positive Einordnung des Christentums in die geistige Umgebung der ersten nachchristlichen Jahrhunderte, und namentlich des vierten und fünften Jahrhunderts, betrifft, wird im Späteren in Abschnitt 3 ein Interpretationsvorschlag unterbreitet werden. Die - zumindest akademischen - Tendenzen, die dagegen versuchen, den historischen Status der „Spätantike“ positiv neu zu defi-

7 Vgl. dazu auch die Ausführungen von Dirk Cürsgen in der Einleitung seines Beitrags zum vorliegenden Band.

8 Richtig sagt daher García Blanco, José, Juliano, Discursos I-V, Madrid 1979, S. 9: „a Juliano hay que entenderlo no en una perspectiva lineal, sino como cúmulo y ejemplo de las contradicciones de su época“.

9 Ortega y Gasset, José, Ideen für eine Geschichte der Philosophie, in: José Ortega y Gasset, Vom Menschen als utopischen Wesen, Hg. E. Straub, Zürich 2005, S. 131-200, hier 135. 
nieren, lassen sich in Aussagen wie der folgenden von Peter Brown ablesen, in denen sie gleichsam kulminieren:

Als ,gelernter' Mediävist, der sich lange mit der Geschichte des späten vierten, des fünften und sechsten Jahrhunderts befaßt hatte, vermochte ich jenen Darstellungen der spätantiken Zivilisation nicht zu folgen, die deren beherrschende Kennzeichen aus einer Stunde des Zusammenbruchs, der Desillusionierung, der Flucht vor den widrigen Realitäten einer scheiternden Gesellschaft ableiten wollten. In meinen Augen war das spätere Imperium eine sehr geordnete Welt, zugleich aber auch eine überraschend schöpferische Welt. Sie beeindruckte mich vor allem als eine Welt, in der die betonte Hinwendung zum Übernatürlichen weit davon entfernt war, Weltflüchtigkeit zu fördern, sondern im Gegenteil in ganz ungewöhnlichem Maße das Sicheinlassen auf das Diesseits, durch Schaffung neuer bzw. die Reform von alten Einrichtungen, zu rechtfertigen schien; [...] Als Mediävist mußte ich mir sagen, daß diese Einrichtungen, die in den meisten Büchern mit dem katastrophalen „Niedergang und Verfall“ der römischen Welt in Verbindung gebracht wurden, in Wirklichkeit für ein weiteres Jahrtausend die Grundlage einer organisierten Gesellschaft bildeten. Wie sollte es zugehen, daß aus jenen angsterfüllten Träumern, denen die „Krise des dritten Jahrhunderts“ angeblich keine Hoffnung mehr im Diesseits gelassen hatte, binnen einer einzigen Generation jene bewundernswert tatkräftigen Menschen hervorgingen, die ich aus dem vierten Jahrhundert kannte? ${ }^{10}$

In impliziter Auseinandersetzung mit Forschungstendenzen, wie sie etwa mit den Arbeiten von Eric Robertson Dodds ${ }^{11}$ und deren Fortschreibern in Verbindung zu bringen sind, diagnostiziert Brown die Spätantike zu Recht als eine homogene Eigenzeit, deren ,neu artikulierter Glaube an die Gegenwart“ in unproblematischer Weise identisch ist mit dem Glauben an „die Gegenwart übernatürlicher Mächte in den menschlichen Dingen“. ${ }^{12}$

Man täte also vielleicht besser daran, den Konflikt zwischen Julian und dem Christentum, zwischen Gnostik, orthodox kirchlicher Theologie und ,heidnischem Platonismus" in einem anderen Kontext und (um es einmal so auszudrücken) auf gleicher „Augenhöhe“ und mit gleichem Epochenanspruch ausgetragen $\mathrm{zu}$ betrachten. Gerade der Platonismus, dem Julian huldigt und der gleichzeitig die Begriffs- und Begreifenssprache des christlichen Denkens zu jener Zeit wird, könnte dafür einen Weg weisen. Denn, wie es Heinrich Dörrie einmal knapp auf den Punkt gebracht hat:

Mit einer Aussage ,... war Platoniker' ist von etwa 220 n.Chr. an sehr wenig gewonnen. Der Platonismus gewann - fast schlagartig - eine erhebliche Breitenwirkung. Platonische Fachsprache wurde zum Vehikel nahezu jeder philosophischen Diskussi-

10 Brown, Peter, Die letzten Heiden, Frankfurt a.M. 1995, S. 22f.

11 So Dodds, Eric Robertson, Pagan and Christian in an Age of Anxiety, Cambridge 1965. Vgl. als Antwort auf Dodds auch: Pagan and Christian Anxiety: A Response to E. R. Dodds, Hg. Robert C. Smith, Washington 1984, sowie Lane Fox, Robin, Pagans and Christians, New York 1987, S. 64-66.

12 Brown (Anm. 10), S. 23. 
on. Aber auch die absichtlich dunklen Offenbarungen der hermetischen Schriften ,platonisieren'. Es dürfte schwer sein, Prosa-Autoren (...) des 3., 4. und 5. Jahrhunderts zu benennen, die nicht irgendwie eine Einwirkung des Platonismus erkennen lassen. $^{13}$

Damit war der Platonismus ein Phänomen, so fährt Dörrie in überzeugender Ausführung weiter fort, das auf allen Ebenen unverkennbare Wirkungen ausübte und normativ in Formgebung und als Inhaltsvorgabe wirkte. - Es sollte für das Folgende also nicht übersehen werden, dass der Gebrauch von „Platonismus“ und „platonisch“ (vielleicht nicht durchgehend, aber doch sehr häufig) im Sinne einer Synekdoché geschehen muss, wo einmal der weitere Begriff - Platonismus als Denk- und Ausdrucksart -, ein andermal die engere Auffassungsweise - der Platonismus als Einzelschule oder Hairesis - erst den Sinn der Konfrontation oder Integration dem christlichen Denken gegenüber erschließt. Anders scheint dem Problem für Julians Zeit und geistige Umgebung auch nicht angemessen beizukommen zu sein: Ähnlich also, wie man im Deutschen von „Tag“ im weiteren Sinn der Bezeichnung von vierundzwanzig Stunden zu sprechen gewohnt ist und doch gleichzeitig mit „Tag“ ebenso nur die lichten Stunden dieses Zeitraums benennen kann. Nach der einen Auffassung wird dann der Tag als Unterschied zur Nacht gelten, in der anderen wird er die Nacht miteinschließen. ${ }^{14}$

Vielleicht ließe sich, zumindest aus geistesgeschichtlicher Warte, für diese Jahrhunderte statt etwa von „Spätantike“ und „Patristik“ (was das fragwürdige „alt versus neu“ Schema oder eine latente Epochenverschiedenheit mit anderen Worten wiederholen würde) also adäquater von einer eigenen - oder zumindest eigenständigen - Epoche sprechen, die im Platonismus sensu lato ihre besondere und weithin identifizierende Form gefunden hat. Eine Form, die ein grundlegendes Einheitsmoment bildet, das wiederum alles, was an bestimmenden „Einflüssen“ oder als „Synkretismus" der Epoche gerne methodisch einheitsverweigernd unterstellt wird, zu widerlegen imstande ist. ${ }^{15}$ Und eine Form mithin, die mächtig

13 Dörrie, Heinrich, Die platonische Philosophie des Kelsos in ihrer Auseinandersetzung mit der christlichen Theologie, Göttingen 1967, S. 50.

14 Daran, diese Differenzierung von Platonismus im engeren und im weiteren Sinn nicht genügend beachtet zu haben, kranken viele Zuordnungsversuche von christlichem Denken und platonischer Philosophie, wie etwa die prominente Formelsammlung von Fabricius, Cajus, $\mathrm{Zu}$ den Aussagen der Griechischen Kirchenväter über Platon, in: Vigiliae Christianae 42 (1988), S. 179-187.

15 Eine mit Recht sehr kritische Bestandsaufnahme der Begriffsverwendung von „Einfluss“ und „Synkretismus“ als geschmacksgebundenes Interessenvokabular in der Beurteilung der ersten nachchristlichen Jahrhunderte im Sinne einer geistig unselbständigen Epoche bietet McEvoy, James J., Neoplatonism and Christianity: Influence, Syncretism or Discernment?, in: The Relationship between Neoplatonism and Christianity, Hg. Th. Finan/V. Twomey, Dublin 1992, S. 155-170, insbesondere 160f. McEvoy legt dabei den Finger insbesondere auf die Tatsache, dass Strömungen innerhalb der christlichen Theologie des 19. Jahrhunderts eine unbarmherzige Tendenz zeigten, das vermutete rein Christliche von aller hellenischen Einmischung zu purgieren. Auf der anderen Seite des Spektrums steht der klassizistische Pur(g)ismus zusammen mit dem Vorwurf Nietzsches, das Christentum habe Europa um das geistige Erbe der Antike gebracht. 
über der Gesellschaft und den geistigen Ausdrücken dieser Zeit liegt und sie in ihren reichen Möglichkeiten offenbar zu dem bildet, was sie ausmacht. ${ }^{16}$ Eine prägnante Form auch, die ganz und adäquat auszufüllen sich verschiedene Strömungen mit eigenen Anliegen und Inhalten, die christliche Lehre, gnostische Gebäude, und eben auch die pagane philosophische Richtung, für die Julian steht, streiten wie Einsiedlerkrebse um eine leere Behausung, die sie im Prinzip alle schon ihr eigen nennen. ${ }^{17}$ In seiner eigenen Weise hat Oswald Spengler in seinem umstrittenen geschichtsphilosophischen Werk dafür den Begriff des (vielleicht etwas unglücklich so benannten) „magischen Zeitalters“ zwischen Antike und Abendland (und beide am Saum teilweise überlappend) vorgeschlagen und den hier interessierenden Tatbestand einer "genotypisch“ nicht-hellenischen und „phänotypisch“ stark antikenförmigen Denkart mit dem Begriff „Pseudomorphose“ zu umschreiben versucht: Ein Begriff, den dann später Hans Jonas seiner Gnostikerinterpretation unterlegt hat und der in jüngster Zeit etwa von Michael Erler gerade zur Deutung der inhaltlichen Wandlungen des Platonismus wieder in die Diskussion geworfen wurde. ${ }^{18}$ Eher Versuche wie die letztgenannten und weniger Spengler sollen für das Nachstehende auch den Leitfaden der Überlegungen spannen, denn es kann hier nicht darum gehen, eine Epoche umfassend und in allen Facetten zu charakterisieren, sondern nur darum, die Formen ihres geistigen Selbstausdrucks auf einer bestimmten Argumentationshöhe zu fassen: Die Theo-

16 So ist es doch überhaupt auffällig, dass es von christlicher wie heidnischer Seite beständig Versuche ernsthafter Art gab, die antike Lebensweise, wie sie ebenfalls noch kraftvoll über die Gesellschaft des dritten bis sechsten Jahrhunderts weithin gebot, in der eigenen Existenzweise als wirksam zu erkennen, aber auch, sie versuchsweise abzulegen und eine andere Lebensweise zur eigenen zu erklären: $\mathrm{Zu}$ den derartigen Versuchen, die wir kennen, gehört der CassiciacumKreis um Augustinus, der Trierer Hieronymus-Kreis, die Gemeinschaften der Wüstenväter, christliche und heidnische „Säkularkongregationen“, usw. Vgl. dazu etwa Aris, Marc-Aeilko, Cicero: ,Der Traum des Hieronymus' und das Trauma der Christen, in: Mittelalterliches Denken. Debatten, Ideen und Gestalten im Kontext, Hg. Ch. Schäfer/M. Thurner, Darmstadt 2007, S. 1-13, hier 3-7, sowie Hadot, Pierre, Philosophie als Lebensform, Berlin 1991, S. 48-65. Genauso auffällig ist aber, dass sich diese Existenzalternativen keineswegs dazu aufrafften oder aufraffen mussten, aus der phänotypisch gleichartig philosophischen Grundform der Geistbetätigung jener Jahrhunderte auszubrechen (nämlich aus der platonischen), ja sie sind sogar meistens ihre Träger.

17 Dieser oft beschriebene „Synkretismus“ der Epoche könnte ohne ein am Grunde verbindendes Moment nicht bestehen, also nicht ohne eine einende Formgebung. So sagt García Blanco, Juliano (Anm. 8), S. 8: „Juliano, contra lo que él cree, no representa el ideal helénico antiguo, sino [...] sus ideas, mezcla de racionalismo, neoplatonismo y teurgía, con un severo ideal ético ¿estoico o cristiano? - impregnado de anhelos místicos, son más bien el testimonio de la evolución espiritual ya desde el siglo II de la Era“.

18 Vgl. Spengler, Oswald, Der Untergang des Abendlandes, Band 2, München 1922, S. 227-235 und öfter; die Einleitung von Jonas, Hans, Gnosis und spätantiker Geist, Göttingen ${ }^{8} 1966$; siehe auch die diesbezügliche Ankündigung bei Erler, Michael, ,Sokrates in der Höhle‘. Argumente als Affekttherapie im Gorgias und im Phaidon, in: Platon verstehen, Hg. M. van Ackeren, Darmstadt 2004, S. 57-68, hier 68. 
logie des Christentums, die platonische Exegese der heidnischen Religion, die Denkart der gnostischen Strömungen, und dergleichen mehr.

Dabei hat der Begriff „Pseudomorphose“, wenn er auf die vieldiskutierte Frage nach dem Verhältnis von Platonismus und Christentum (oder auch zu anderen geistigen Bewegungen) angewendet wird, das bedenkliche Problem an sich, dass er schnell den Eindruck erweckt, hier würde einem strukturell eigenbestimmten Inhalt eine womöglich vollkommen artfremde Form nur äußerlich übergestülpt. Die Herkunft des Begriffs aus der Mineralogie und Veranschaulichungsbeispiele wie die mit den Einsiedlerkrebsen (die sich durchaus schon mal groteskerweise um leere Bierdosen als Behausung zanken) leisten dem ja auch Vorschub. Endre von Ivánka etwa hat daher fälschlicherweise vom Platonismus als dem „Gewand“ oder der äußeren Hülle des Christentums gesprochen, und viele sind ihm in dieser Ansicht vorangegangen und gefolgt. ${ }^{19}$ Der Fehler ergibt sich in solchen Fällen daraus, dass man die Form, die morphé, als bloß äußere auffasst (wie das bei geologischen Pseudomorphosen der Fall ist). Man vergisst dabei allzu häufig, oder übersieht geflissentlich, dass hier zur angemessenen Deutung doch eher die Strukturform gemeint sein muss, nicht nur eine Präsentationsform also, nicht nur eine äußere figura oder ein umrisshaftes lineamentum, wie die Schulphilosophie differenzierend sagt, sondern eine Durchformung, die sich dann zwar auch äußerlich gestaltgebend auswirkt, das Geformte jedoch im Tiefsten definierend bestimmt. ${ }^{20}$ Damit aber ist eine Pseudomorphose im strengen Auffassungssinn ohnehin ein Oxymoron. Forma dat esse, heißt es deswegen zu Recht in der philosophischen Tradition, ${ }^{21}$ die somit auch unterscheiden kann, dass etwa ein Hirsekorn zwar die figura eines Pferdes haben kann (das wäre möglicherweise eine Art zufälliger „Pseudo-Morphe“), niemals aber als Hirsekorn die forma eines Pferdes, die es unter anderem zum Laufen, zum Wiehern und zur Fortpflanzung mit anderen Pferden brächte. ${ }^{22}$

Die Stärke des Pseudomorphose-Begriffs (für die ich im Nachstehenden auch plädieren möchte) liegt dafür darin, dass hier anders als in der eben vorgestellten hylemorphistischen Interpretation in einsichtsförderner Weise Wert auf die Feststellung gelegt wird, dass es insbesondere die Form sein kann, die das zeitlich sich Durchhaltende darstellt, und in verschiedenen Transformationen als identifi-

19 Von Ivánka, Endre, Plato Christianus. Übernahme und Umgestaltung des Platonismus durch die Väter, Einsiedeln 1964, S. 285.

20 Richtig daher Kobusch, Theo, Christliche Philosophie. Die Entdeckung der Subjektivität, Darmstadt 2006, S. 30, über das Verhältnis von Christentum und platonischer Philosophie: „Die Philosophie war für die Apologeten und Kirchenväter [...] mehr als nur eine Hülle oder ein Kleid, in die die christliche Lehre gesteckt wurde. Das Christentum war vielmehr durch und durch in seiner Substanz eine Form der Philosophie“.

21 So stellt die Form eben die Vollendung des Seienden dar und seine eigentliche Wesenart: forma vel est ipsa natura rei [...] vel est constituens ipsam rei naturam (Thomas von Aquin, Summa theologiae III q.13 a.1).

22 So das Beispiel bei Walter Burleigh, Tractatus de formis, Prima pars (Frederick J. Down Scott, Walter Burley's Treatise De formis, München 1970, S. 13f.). 
zierende Formung präsent bleibt. Wenn sich die gnostischen Denominationen, die christliche Theologie und die Philosophie Julians in ihrer Zeit alle gleichermaßen als die Vollendungsform des platonischen Denkens empfinden und sich danach doktrinal einrichten, so kann man in diesem Sinne durchaus (vom historischen Blickwinkel her betrachtet) von einer Pseudomorphose im Hinblick auf den antiken Platonismus sprechen, der als Form nach wie vor ihre geistige Epoche dominiert und ihnen (vom systematischen Blickwinkel her angesehen) ihr Sein gibt, indem er ihnen seine Form einprägt und damit auch ihre „Inhalte“, zwar nicht unbedingt hergibt, aber doch in ein Raster stellt und mitdefiniert. Nur aufgrund dieser Voraussetzung lässt sich dann, wenn überhaupt, für dieses Problem im adäquaten Sinn von „Form“" und „Inhalt" differenzierend sprechen. ${ }^{23}$

Im Folgenden möchte ich auf der Grundlage und in Weiterführung dieser Überlegungen versuchen, die für Julians angeblichen „Restaurationsversuch“ interessierenden Positionen anhand von Konvergenzen und Divergenzen auf dem gemeinsamen Hintergrund des platonischen Denkens zu sortieren und zu erklären - und damit zugleich die Konvergenzen und Divergenzen selbst. Statt von ,,platonischer Restauration“ und „christlichem Neuanfang“ ergibt sich damit eher das Bild eines Kampfes um die Charakteristik einer gemeinsamen Epoche. Das wird zunächst anhand von (allerdings gezwungenermaßen nur wenigen) ausgesuchten Themenfeldern und Belegstellen für die tragenden Gemeinsamkeiten geschehen, die, so die Hoffnung, die entsprechenden Grundmomente von paganem Schulplatonismus, christlichem Denken und gnostischer Lehre auszudeuten und zu illustrieren in der Lage sind (Abschnitt 3). Sodann soll das intrikate Verhältnis der verschiedentlich und in verschiedenem Sinne auf einer fundamental platonischen „unity of attitude“ gegeneinander stehenden Lehren dieser drei erläutert werden (Abschnitt 4). Der Schluss gehört einer weiterführenden Ergebnisbetrachtung (Abschnitt 5).

\section{Julian und das Christentum: Die Grundtendenz hinter den Einzelproblemen}

Die oft seltsamen Übereinstimmungen, welche die ansonsten verbittert miteinander im Hader liegenden Gnostiker, Christen und „magischen“ Heiden (um bei diesen drei bekanntesten und vielleicht aus heutiger Warte tatsächlich bedeu-

23 Für richtig halte ich daher das Fazit zur Diskussion der „Spätantike“ bei Whittaker, John, Plutarch, Platonism and Christianity, in: Neoplatonism and Early Christian Thought. Essays in Honour of A.H. Armstrong, Hg. H.J. Blumenthal/R.A. Markus, London 1981, S. 50-63: "It has often been remarked [...] that all Greek philosophy is theology. Nowhere is this generalization more valid, however, than in the first centuries after Christ. I have tried to illustrate the intellectual life of this period by presenting a number of characteristic themes which cut across all the boundaries which are traditionally set up between pagans and Christians, Jews, Stoics and Platonists. In spite of distinctions of sect and school the period possesses a fundamental unity of attitude", etc. (S. 61). 
tendsten Grundansätzen der Epoche zu bleiben ${ }^{24}$ ) in bestimmten identifizierenden Punkten ihrer geistigen Selbstdarstellung aufweisen, ließen sich somit doch vielleicht besser erklären, als mit der Annahme, dass Julian eine Restauration des Überlebten gegen das kräftig neu Aufblühende versucht habe. Und vielleicht auch etwas anderes, was die Beschäftigung mit Julian dann doch wieder äußerst „spannend" macht: Denn wenn man sich gemeinsam auf dem Boden oder in der integrierenden Form des Platonismus in seiner damaligen Ausprägung wiederfindet, auf selbem Terrain also die eigenen Inhalte gegeneinander auftreten lässt, dann lassen sich diese Inhalte sehr viel besser in ihren unverwechselbaren Charakteristika erkennen, ohne dass man befürchten müsste, man rede von vornherein aneinander vorbei, da man keine gemeinsame Form des Ausdrucks und kein gemeinsames Feld der Auseinandersetzung findet. Solche Gemeinsamkeit macht auch zuweilen die Eigenständigkeit oder „Jeweiligkeit“ einer Epoche erst aus, oder macht sie zumindest deutlich. Wer in den Annahmeformen der Wissenschaftssprache, der Seelenlehre, der Definition des Göttlichen, des sakralen Kaisertums, des mystischen Erkenntniswegs und dergleichen so weit übereinkommt, dass man auch von vornherein versteht, worüber der andere spricht, der wird auch den Kern der unüberbrückbaren Differenzen im Anderen gegenüber dem Eigenen nicht lange suchen müssen und die Auseinandersetzung gezielt und unverblümt darauf zuführen. In der Bezeichnung „Gegenplatonismus“, die Dörrie für das Christentum der ersten Jahrhunderte wählte, ${ }^{25}$ steckt daher (gegen Dörries Absicht) eine bezeichnende Wahrheit selbst dann, wenn man Dörries implizite Nomenklatur mitmacht, unter „Platonismus“ nur dessen pagane Richtung anzunehmen, und zwar wegen der Doppeldeutigkeit des Präfixes „Gegen-“. Wie ein „Gegenspieler“ zwar dasselbe Spiel nach denselben Regeln spielt und gleichwohl antritt, die weiteren Spieler in diesem selben Spiel zu übertreffen und womöglich niederzuringen, so ist weitgehend auch das Christentum jener Zeit genauso (positiv gesprochen) ein wi(e)derspiegelndes Gegenbild des nichtchristlichen Platonismus wie (im negativen Sinne) ein Anti-Platonismus: Das Christentum war im Platonismus wie im Spiegel zu sehen, aber für pagane Platoniker und die Christen selbst darin oft fast nicht wiederzuerkennen.

Wie ein geraffter Beleg dafür verläuft das Leben des vielleicht berühmtesten geistigen Epochenvertreters, dessen Biographie sich fast wie ein immer wieder neu unternommenes Hineinwachsen in diese Form ausnimmt, wie ein ständig neues Ausmessen des Horizonts, in dem er steht und stehen will: Die „Bekehrungen" des Kirchenvaters Augustinus vom Rhetor - einem Vertreter der ebenfalls epochenkennzeichnenden „Bildungsideologie“ - zum manichäischen Gnostiker,

24 Weitere wären denkbar, wie etwa die neupythagoreischen Richtungen in ihrem Entwicklungszusammenhang mit dem Platonismus: Vgl. dazu die Studien von John Whittaker, zum Beispiel: Neopythagoreism and the Transcendant Absolute, in: Symbolae Osloenses 48 (1973), S. 77-86, sowie Ders., Epekeina nou kai ousias, in: Vigiliae Christianae 23 (1969), S. 91-104.

25 Dörrie, Heinrich, Was ist spätantiker Platonismus? Überlegungen zur Grenzziehung zwischen Platonismus und Christentum, in: Theologische Rundschau 36 (1971), S. 285-302, hier 293. 
zum platonischen Philosophen, und (vielleicht sogar „zwei Mal“) zum Christen, sind häufig und mit einigem guten Gespür der Interpreten als „bloße Wandlungen" eines, und zwar eines platonischen, Grundansatzes in einer Person kritisiert worden. Die Kritik ist aber nur unter der Hinsicht nicht ganz unangemessen, dass es hier zu steten Umformungen der einen Form kam, zu genuin Augustinischen Transformationen der einen geistigen Formation, um die er fortwährend als die seinige kämpfte. ${ }^{26}$ Die Kritik verliert ihre Berechtigung aber schließlich deswegen, weil genau das dem Augustinus seine qualifizierte Entscheidung für die eine und gegen die andere dieser einzelnen Denkformen ermöglichte und einen klaren Blick für die differentia specifica der einen gegenüber der anderen im epochebildenden Gemeinsamen. Kein Wunder denn auch, dass die Suche der christlichen Theologen im 19. und 20. Jahrhundert nach dem, was man gerne das ,spezifisch Christliche" nannte, meist nur dann ohne Peinlichkeiten ablief und wirklich belohnt wurde, wenn dieses Spezifische in den oder über die Auseinandersetzungen gesucht wurde, wie sie in den ersten paar Jahrhunderten nach Plotin das geistige Klima beherrschten. ${ }^{27}$

Im Ersten Petrusbrief $(3,15)$ wird als eine Grundanweisung für das „qualifizierte Christsein" genannt, man solle jederzeit für die Hoffnung, aus der man lebt, Rede und Antwort stehen können. Ähnlich drückt Anselm von Canterbury gut

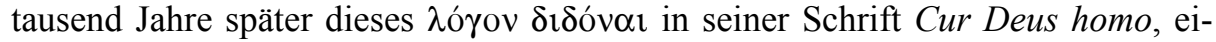
nem erstaunlichen - nach philosophiehistorischer Standardwertung durch und durch „platonisierenden“ - Werk über die zwingenden Vernunftgründe für die Menschwerdung Gottes, aus: „Es scheint mir eine grobe Nachlässigkeit, wenn wir, nachdem wir im Glauben gefestigt sind, uns nicht vernünftig zu verstehen bemühten, was wir denn da glauben“. ${ }^{28}$ Anselm formuliert hier den Anspruch der christlichen doctrina, man könne die Geheimnisse des christlichen Glaubens, auf denen das Leben des Christen ruht, auch ohne die Erfahrung seiner geoffenbarten Inhalte einsehen und müsse das eigentlich sogar (dass „Geheimnis“ in diesem Fall der christlichen Auffassung nicht „verborgenes Exklusivwissen“ heißen kann, liegt zutage). Wie zum Beleg dafür sagt Anselms Aufsehen erregender Zeitgenosse Peter Abaelard in seinem Soliloqium, dass das allein schon daran zu sehen sei, dass die antiken, insbesondere platonischen Philosophen ohne Kenntnis der Schrift und allein durch vernünftige Überlegung der christlichen fides quae sehr

26 Zum Problem vgl. - cum grano salis - auch McEvoy, Neoplatonism and Christianity (Anm. 15), S. $168 f$.

27 Es ist daher nach wie vor ein Thema von geradezu orthodoxiedefinierendem Interesse, und vielleicht hat John Dillon recht mit der Bemerkung: „It is, indeed, one of the few areas of classical scholarship in which one could conceivably get oneself excommunicated" (Dillon, John, Origen and Plotinus: The Platonic Influence on Early Christianity, in: Finan/Twomey (Anm. 15), S. 7-26, hier 7).

28 Anselm von Canterbury, Cur Deus homo, S. Anselmi Opera Omnia, ed. Franciscus Salesius Schmitt, Edinburgh 1940-1961, II, S. 48. 
viel näher gekommen seien als die Propheten des auserwählten Volkes. ${ }^{29} \mathrm{Ob}$ Anselm dem zugestimmt hätte, ist nicht ausgemacht, denn das Argument Abaelards stellt die biblischen Autoritäten den heidnischen Vernunftlehrern in einer Weise entgegen, die Anselm wohl für absurd gehalten hätte, da doch rechte Vernunft und biblische Offenbarung im Grunde übereinkommen und nicht solcherart als „besser“" oder „,schlechter“, „näher“ oder „ferner“ von der Wahrheit gegeneinander aufgefahren werden können. ${ }^{30}$ Wenn es allerdings im Glauben ein Erfahrungsmoment gibt, dann steht für Anselm fest: Aus Erfahrung wird man klug, und es wäre fahrlässig, es dann ausgerechnet aus der Glaubenserfahrung nicht zu werden. Anselm macht sich zum Echo von berühmten Aussagen des Augustinus, wie dass die Platoniker, so man nur wenige ihrer Worte oder Aussagen verändern würde, eigentlich wie für Christen gehalten werden könnten (paucis mutatis verbis atque sententiis Christiani fierunt; so De vera religione 4,7). ${ }^{31}$ Augustinus selbst weiß sich dabei offenbar in einer Tradition, die in Paulus den Vollender des Platonismus, oder zumindest von dessen sachlichen Grundanliegen, sehen konnte, und die womöglich daher auch keine Probleme etwa damit gehabt haben könnte, sogar die Gesichtszüge Plotins in die Ikonographie ihrer Paulusdarstellungen aufzunehmen. $^{32}$

Rede und Antwort stehen soll man also für sein Leben als Christ können, sagt der Petrusbrief, und Anselm versinnbildlicht geradezu den letzten Höhepunkt einer langen Überlieferungslinie, die zeigen wollte, wie das zu bewerkstelligen

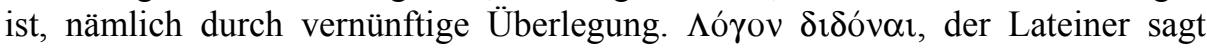
dazu rationem reddere, also „den Logos wiedergeben“, „Vernunft hergeben“

29 Vgl. Peter Abaelard, Soliloquium, Peter Abaelards philosophische Schriften, Hg. B. Geyer, Münster 1919-1933, S. 887; ähnlich in der Theologia christiana, S. 149 und S. 159. - Und, da schon eingangs von Droysen die Rede war: Auch dessen 1831 verteidigte (und freilich unter ganz anderen, nämlich eben Hegelschen Vorgaben formulierte) Doktorthese hieß, gestützt auf die weitere Begriffsbedeutung von „Religion“, „daß die griechische Religion der christlichen näherstehe als die jüdische"; im lateinischen Original unter Verwendung des Begriffs doctrina: „A doctrina Christiana Graecorum quam Iudaeorum religio propius abest“" (Christ (Anm. 5), S. 58 mit Anm. 22).

30 So wird von den Interpreten auch bisweilen mit beachtlich guten Gründen in Abrede gestellt, dass es jemals zu einer „Begegnung“ von Christentum und griechischem Geist gekommen sein könnte, da „beide nie getrennt waren“: Siehe Kobusch (Anm. 20), S. 29, mit den entsprechenden Belegzitaten.

31 Fuhrer, Therese, Die Platoniker und die civitas Dei, in: Studia Patristica 33 (1997), S. 83-87, führt in diesem Sinne eine ganze Reihe von Übereinstimmungen zwischen Platonismus und Christentum auf, die sich in den Augustinischen Aussagen finden lassen. Als Ergänzung (und als Gegengewicht) zu Fuhrer interessant sind die Ausführungen bei House, Denis, St Augustine's Account of the Relation of Platonism to Christianity in the De Civitate Dei, in: Dionysius 7 (1983), S. 43-48, und Suchla, Beate Regina, Verteidigung eines platonischen Denkmodells ei-

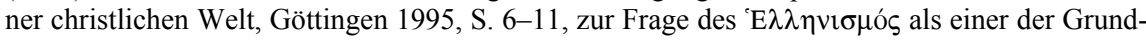
häresien im frühen Christentum.

32 Dazu Schäfer, Christian, The Philosophy of Dionysius the Areopgagite, Leiden/Boston/Köln 2006, S. 163-173, und Ders., Unde malum. Die Frage nach dem Woher des Bösen bei Plotin, Augustinus und Dionysius, Würzburg 2002, S. 349f. 
muss man demnach als Christ also können, um nicht fahrlässig zu glauben. ${ }^{33}$ Nun ist $\lambda$ ó $\gamma$ os ein schier unübersetzbarer Begriff, doch pflegte ein alter Griechischprofessor, den ich gerne hörte, zu sagen, dass man nicht fehlgehen wird, wenn man unter dem $\lambda$ ó ${ }_{0} \varsigma$ in jedem Fall ein ,,vernünftiges Sinnganzes, das sprachlich oder anderswie einleuchtend geäußert werden kann" verstünde. In dieser Weise fassen auch Sokrates und viele andere antike Philosophen das $\lambda$ ó legen rational nachvollziehbar Rechenschaft von dem ab, was sie als vernünftig zu äußerndes Sinnganzes ihrer Weltsicht vertreten, meist in Argumenten, aber durchaus auch durch ihr Leben und - wie im Fall des Sokrates ganz prominent durch ihren Tod.

Das Christentum der Anfangsjahrhunderte hatte sich nun gerade zu diesen Philosophen und ihren Schulen in Konkurrenz gesehen, weniger zu irgendwelchen der im Kaiserreich farbenfroh aufsprießenden oder seit jeher bestehenden Religionen. Und noch bei Augustinus ist das ganz natürlich so: Was das Christentum ausmacht, beschreibt er in seinem Buch De doctrina christiana, und er benutzt in diesem programmatischen Titel das Wort, mit dem die Philosophenschulen seiner Zeit ihre Lehrgebäude bezeichneten: doctrina. Seine Schrift De vera religione dagegen beschäftigt sich keineswegs mit dem christlichen Glauben als einer Religion gegenüber anderen ,unwahren“ Religionen, sondern mit „,der rechten Religiosität“ oder „Frömmigkeit“, also einer grundsätzlichen Einstellung. Die Forschung hat sich mittlerweile zu dem beglückwünschenswerten Konsens durchgerungen, dass auch jene Passagen etwa bei Paulus, die eine Kritik an der Philosophie vermuten lassen könnten (Kol 2,8 oder 1 Kor 1,17-21; 3,19) lediglich gegen einzelne Lehren bestimmter Philosophenschulen auftreten ${ }^{34}$ und ihnen gegenüber die bessere Vernunft der christlichen doctrina und der daraus resultierenden besseren Lebenshaltung zeigen wollen (so akzentuiert auch Apg 17,18-34 im Hinblick auf Epikureer und Stoiker) - ganz ähnlich gilt das für Aussagen wie die des Gregor von Tours von der philosophorum inimica Deo sapientia und Kognaten. ${ }^{35}$

Augustinus, Clemens von Alexandrien, Origenes, Basilius, Eusebius und wie sie alle heißen sahen dementsprechend im christlichen Glauben nichts Vernunftwidriges oder Vernunftfernes, sondern gerade einen vernünftigen, stichhaltigen Lebensentwurf, der die lebensleitenden Welterklärungen anderer Philosophenschulen überbot und insofern der „logische“ war: ${ }^{36}$ Im Christentum sei das ver-

33 Daneben gab es allerdings tatsächlich bereits früh ,fideistische“ Kreise im Christentum, die im

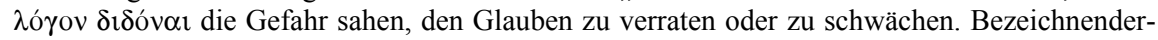
weise werden sie sowohl von christlichen wie christenfeindlichen Philosophen in dieser Auffassung kritisiert und mit ganz ähnlichen Argumenten bekämpft. Vgl. Kobusch (Anm. 20), S. 97f. mit Belegen.

34 Vgl. Horn, Christoph, Antike Lebenskunst, München 1998, S. 233f.

35 Gregor von Tours, Liber in gloria martyrum, Gregorii episcopi Turonensis miracula et opera minora, B. Krusch (Hg.), Hannover 1969, 37, 19-38, 8.

36 Vgl. Kobusch (Anm. 20), S. 27, 53, 152f., und öfter. 
nünftige Nachdenken über Gott, die Welt und den Menschen zur Vollendungsgestalt gelangt. Die Christen seien daher, so Justin, diejenigen, die wahrhaft „dem

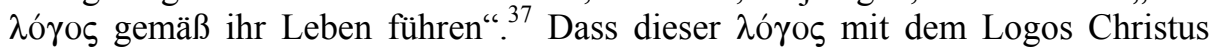
gleichzusetzen sei, dem gemäß die Christen ihr Leben führen, und auch die Weisheit, die der Philosoph, also nach der interpretatio platonica wörtlich der Weisheitsliebende, sucht und anstrebt, im menschgewordenen Logos zum Ausdruck gebracht worden ist, werden Clemens, Augustinus, Johannes Chrysostomus und all die anderen nicht müde zu betonen: Christen sind solche, die in Denken und Lebensanlage das vernünftige Sinnganze der Wirklichkeit als in Christus einleuchtend zum Ausdruck gekommen begreifen. ${ }^{38} \mathrm{Im}$ Gegensatz zu anderen lebensgestaltenden Weltauffassungen wie etwa "der Philosophie gemäß Epikur“ oder „der Philosophie gemäß Pythagoras“ (der seinen Anhängern als Gottessohn und aus dem Tode Wiedergekommener galt ${ }^{39}$ ), bezeichnen die Kirchenväter ihre

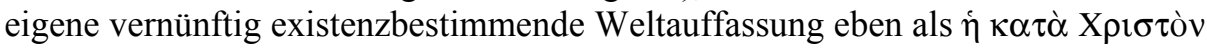

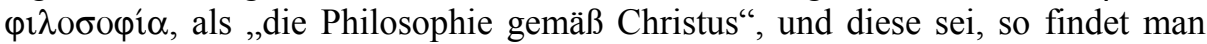
das bei Augustinus (Contra Julianum IV 72), dann auch die vera philosophia, die wahre Philosophie im Sinne von: Die Philosophie, in der sich die Wahrheit wiedergefunden hat.

Es ist daher also weniger auffällig oder verwunderlich als manche möchten, dass Julians Opposition gegen das Christentum teilweise auch „,christliche Ausformungen" annehmen konnte: Liturgische Übernahmen aus dem sakramental verstandenen christlichen Ritualbestand konnten einem Platoniker einleuchten (vgl. Salustios, De dis et mundo IV 1) und gehörten zu Julians Reform und zu seiner Konzeption einer im konkurrierenden Gegensatz zur christlichen Kirche begründeten „Heidenkirche“ genauso selbstverständlich wie moralische Imitationen der praktizierten christlichen charitas im Sinne eines „Sozialsystems“, ${ }^{40}$ für

37 Vgl. McEvoy (Anm. 15), S. 168: "Platonism finds its true fulfilment in Christianity". Das Justin-Zitat (aus Apologie 46; PG 46, 397) und weitere Belege bei Horn, Lebenskunst (Anm. 34), S. 235 mit Belegzitaten.

38 Vgl. Kobusch (Anm. 20), S. 29, mit Belegzitaten, weitere einschlägige Belege finden sich dort Anm. 19 auf S. 156 und Anm. 21 auf S. 157.

39 Vgl. zu solchen philosophisch-hagiographischen Gemeinsamkeiten die Studien von du Toit, David S., Heilsbringer im Vergleich: Soteriologische Aspekte im Lukasevangelium und Jamblichs Vita Pythagorica, S. 275-294, und Dillon, John, Die Vita Pythagorica - ein „Evangelium“"?, S. 295-302, in: Jamblich, Pythagoras. Legende - Lehre - Lebensgestaltung, Hg. M. von Albrecht/J. Dillon/M. George/M. Lurje/D. S. du Toit, Darmstadt 2002. Auch die Vita Plotini des Porphyrios wird ja in diesem Sinne gerne in die Nähe der Evangeliendarstellungen gerückt.

40 Julian begegnet damit einem häufig, aber nicht unbedingt durchgehend anzutreffenden Vorwurf von christlicher Seite an die Platoniker, nämlich die Praxis zu vernachlässigen: Vgl. Kobusch (Anm. 20), S. 39, und Horn (Anm. 34), S. 236, sowie Domanski, Juliusz, La philosophie, théorie ou manière de vivre?, Fribourg/Paris 1996, S. 29. Was Julians persönliche, philosophisch motivierte Lebensführung betrifft, hat García Blanco (Anm. 8), S. 9f., recht: „su ascetismo ético está mucho más próximo al de los monjes cristianos que a la vida de los habitantes de Antioquia; [...] so conservadurismo religioso se hace revolucionario al adoptar para el paganismo las formas benéficas del cristianismo, al pedir el ejemplo de vida a sus sacerdotes y al intentar erigir 
dessen Grundlage es jedenfalls tragende Übereinstimmungen in Menschenbild und Ethik zwischen christlicher und julianisch-platonischer Auffassung geben musste. ${ }^{41}$ Die „Denkform“ der Epoche forderte es auch geradezu, dass ,,die betonte Hinwendung zum Übernatürlichen weit davon entfernt war, Weltflüchtigkeit zu fördern, sondern im Gegenteil in ganz ungewöhnlichem Maße das Sicheinlassen auf das Diesseits, durch Schaffung neuer bzw. die Reform von alten Einrichtungen, zu rechtfertigen“, wie Peter Brown zu Recht sagt. ${ }^{42}$

„Platonismus fürs Volk“ war vor diesem Hintergrund mutatis mutandis auch Julians Losung und sie musste es auch sein. ${ }^{43}$ Während sich das Christentum spätestens seit dem dritten Jahrhundert zunehmend ,von der Verkündung auf die Begründung“ verlegte und sich um geistige Hebung und platonische Ausbuchstabierung des Eigenen bemühte, die es erst zur Würde einer Gegnerschaft im Reigen der doctrinae avancieren lie $\beta,{ }^{44}$ geschah gleichzeitig im paganen Platonismus offenbar auch eine teilweise Besinnung auf eine stärkere „Verbreitung“, wo ursprünglich ausschließlich „Vertiefung“ die Leitvorgabe war. In der Umgebung Julians bemühten sich platonische Kompendien um eingängige Darstellungen der Doktrin, Themistios lieferte allgemeinverständliche Paraphrasen der philosophischen Hauptwerke mit Bezug zum Platonismus. Vielleicht beabsichtigte Julian damit auch, einen Fehler zu vermeiden, den er (ähnlich wie heutige Interpreten) bei Kelsos, Porphyrios und anderen Christentumsgegnern erkannt haben wollte. ${ }^{45}$

una iglesia pagana“. Vgl. auch auf S. 18: „se ha podido hablar, con razón, del intento de construcción de una auténtica iglesia pagana".

41 Vgl. dazu Julian, Brief 84 und das lange Brieffragment 89b; sodann Hymnos an Helios 131a, Hymnos an Magna Mater 174b; Gegen den Kyniker Herakleios 229b (Zitate der Werke Julians hier und im folgenden nach den Ausgaben L'Empereur Julien, Euvres Complètes, Hg. J. Bidez/Ch. Lacombrade/G. Rochefort, Paris 1924-1964 und The Works of the Emperor Julian, Hg. W. C. Wright, London/Cambridge 1913-1923 (ND 1954-1961)). Dafür, dass das Projekt einer konkurrierenden „Heidenkirche“ auch von Zeitgenossen so gesehen und interpretiert wurde, spricht die Wunderanekdote des unmöglichen Kirchenbaus bei Gregor von Nazianz (Orationes IV 24ff., PG 35, 552B) und Sozomenos (Historia ecclesiastica V 2,12, PG 67, 1215A).

42 Vgl. Brown (Anm. 10), S. 23. Richtig das Fazit von Whittaker, John, Christianity and Morality in the Roman Empire, in: Vigiliae Christianae 33 (1979), S. 209-225: "Viewed in toto the evidence assembled above indicates conclusively that $[. .$.$] Christians of the early centuries did not$ claim as a distinguishing mark of their religion the extension of charity to include even one's enemies, and that such charity was not held by contemporary pagans to be a unique feature of Christianity. The above evidence suggests on the contrary that the realization of universal charity was the commonly accepted ideal of the ethics of later antiquity to which neither Christians nor pagans could claim, or even attempted to claim, any exclusive right of ownership" etc. (S. 222). Ähnlich Kobusch (Anm. 20), S. 141f.

43 Vgl. Kobusch (Anm. 20), S. 46: „Scharfsichtig hat F. Nietzsche das Eigentümliche dieses Platonismus erkannt, als er das Christentum ,Platonismus für's Volk' nannte“.

44 Vgl. dazu auch Dörrie (Anm. 13), S. 84; sowie Ottmann (Anm. 1), S. 314.

45 Betz, Hans Dieter, Das Problem der Auferstehung Jesu im Lichte der griechischen magischen Papyri, in: Ders., Hellenismus und Urchristentum, Tübingen 1990, S. 230-260, sagt dementsprechend: „Man muß sich ohne Illusion darüber im klaren sein, daß die Schwierigkeiten für Kelsos und ebenso für Porphyrios nicht darin bestanden, daß ihre Argumente nicht ausreichten 
Und selbst zur systematischen Bevorzugung des Griechischen bei Julian lassen sich Parallelen im platonischen Definitionsbemühen der christlichen Theologie finden, etwa, wenn sich einer seiner christlichen Zeitgenossen mokiert, wenn er versuche, auf lateinisch über die Dreifaltigkeit zu reden, könne er die Haupthäresien gar nicht vermeiden. Ein Echo davon findet sich noch bei heutigen Interpreten. ${ }^{46}$

Frappierende inhaltliche Übereinstimmungen, Parallelen in der definierenden Formgebung und implizit oder offen anerkennende gegenseitige Imitationen von Hagiographien, Musterbiographien, Paränesen, philosophischen Lehren in Offenbarungsform, soteriologischen Texten und anderen literarischen Ausdrucksgestalten mehr lassen sich in Christentum, Neupythagoreismus, gnostischen und paganen philosophischen Schriften finden. ${ }^{47}$ Aber auch in tiefer eingreifenden philosophischen Dingen kommt es zum Versuch „überbietender Imitation“, Aufnahme und Transfusion christlichen oder gnostischen Gedankenguts in Julians Eigenreligiosität platonischer Ausführung: So liest sich der weitläufige Anfangsteil der Helios-Schrift des Kaisers (1-7) wie ein Versuch, den Gedanken einer Konsubstantialität des unsichtbaren Lichtgottes mit - lumen de lumine dem sichtbaren zu forçieren, die beide als wesensgleich einer Hervorbringer und Herr der unsichtbaren Welt der rationes aeternae und einer der sichtbar wahrzunehmenden Welt sind, also gleichsam visibilium omnium et invisibilium. ${ }^{48}$ Es gab aber auch im Christentum eine Interpretationslinie, die Gott als „Sonne der Son-

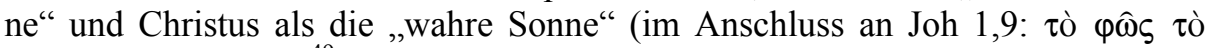
$\dot{\alpha} \lambda \eta \theta \imath v o ́ v)$ benannte. ${ }^{49}$

Dabei stellt Julian Platons Sonnengleichnis dem Christentum als den besseren Entwurf mit dem richtigeren Begriff von Wahrheit entgegen, aus seinem HeliosHymnos und Augustins Illuminationslehre lässt sich der Kampf um die Interpretationshoheit über die platonische Lichtmetaphorik wie an einem bestellten Vorführbeispiel ersehen. Dieses Schema lässt sich motivisch zurückverfolgen bis zur

oder nicht überzeugend vorgetragen worden waren [...]. Ihr Problem bestand vielmehr darin, daß die Zahl der Gebildeten, die sich die religionskritischen Gedanken hätten zu eigen machen können, verschwindend gering war im Vergleich zu den Massen“"(S. 237f.).

46 Vgl. Kobusch (Anm. 20), S. 24.

47 Einen guten Einblick bieten am Beispiel der Vita Pythagorica des Iamblichos und ihrer dementsprechenden „Vernetzung“ die gesammelten Aufsätze von von Albrecht, Michael, Das Menschenbild in Jamblichs Darstellung der pythagoreischen Lebensform, S. 255-274; du Toit, Heilsbringer im Vergleich (Anm. 39); Dillon, Die Vita Pythagorica (Anm. 39); George, Martin, Tugenden im Vergleich: Ihre soteriologische Funktion in Jamblichs Vita Pythagorica und Athanasios' Vita Antonii, S. 303-322, allesamt in: von Albrecht/Dillon/George/Lurje/du Toit (Anm. 39).

48 Julian, Hymnos an Helios 132b-133a; 138d, und öfter. Die Bezugnahme ist vor allem auf Platons Politeia 506d-508c.

49 Beides im Anschluss an platonische Vorgaben, wie Philon von Alexandrien, De specialibus legibus 1, 279, und die Tradition der christlichen Auffassung von Gott als der „Übersonne“ zeigen. Letztere hat noch ihren Niederschlag bei Boethius: vgl. Gruber, Joachim, Kommentar zu Boethius' De consolatione philosophiae, Berlin/New York ${ }^{2} 2006$, S. 377. 
kämpferischen Deutung des Sonnengleichnisses durch Kelsos und ihrer Darstellung bei Origenes. ${ }^{50}$ An der Konkurrenzauslegung um das Sonnengleichnis nehmen aber genauso die Gnostiker und Neupythagoreer mit ihren theologischen Spekulationen teil. ${ }^{51}$ Noch im sechsten Jahrhundert distanziert sich Dionysius Areopagita vom nichtchristlichen Gebrauch der Lichtmetaphorik in der Tradition Julians und bietet, sicherlich in negativer Bezugnahme auf diese, seine christliche Exegese des Sonnengleichnisses. ${ }^{52}$

Der im Helios-Hymnos des Julian (39, 153ab) genannte Gottessohn, der in Menschengestalt heilbringend unter Menschen wandelt, wird wie der Logos des Johannes-Prologs als „Erlöser der Welt" dargestellt, er ist gezeugt, nicht geschaffen, und war vor allem Anfang bei Gott (Helios-Hymnos 22, 144b). Von einer „dritten Hypostase“ im - freilich spezifisch umgedeuteten - Sinne eines „dritten Schöpfers", der aus den beiden bereits genannten hervorgeht, spricht Julian an anderer Stelle ebenfalls (Hymnos an Magna Mater 3, 161d).

Auch soll man sich über die doktrinale Seite und die geistige Eigenart der platonischen Julian-Bewegung und ihrer Implikationen für ihre Bewertung als noch „echt antik“ und gerade daher „nicht christlich“ nicht täuschen: Gerade der für diese Bewegung geschriebene und aus ihr hervorgegangene „platonische Katechismus" (so Geffckens eingängige Analogie) des Salustios zeigt - eben vor allem in der Eigenart als „Katechismus“ oder im Eindruck, ein solcher zu sein viel mehr Anlageverwandtschaft mit der Denkform des Christentums als mit der Religion des klassischen Griechenlands und ihren vollkommen „katechismusfremden" Ausdrucksformen. Nicht, dass das Christentum dabei den unausweichlichen Orientierungspunkt hergeben würde: Vielmehr ist die zugrunde liegende epochale Denkform das Einende. ${ }^{53}$ Auch hier soll Heinrich Dörrie mit einer abschließenden Beobachtung das Wort haben, die, wenn auch cum grano salis zu nehmen, allein schon darin bedenkenswert ist, dass Dörrie sich zutraut, in solcher Exklusivität zu sprechen und dabei gleichzeitig einen Modellbegriff einzuführen, der seinerseits etwas stark Pseudomorphistisches an sich hat:

50 Vgl. Dörrie (Anm. 13), S. 38-42.

51 Vgl. dazu Whittaker (Anm. 24), S. 91-104.

52 Vgl. Dionysius (Pseudo-)Areopagita, De divinis nominibus 697B-7001B, wohl in Bezugnahme auf Julians Helios-Hymnos 16, 140c-141a; Julianisch in der Wortwahl erscheint dabei u.a. das Motiv der ungetrübten Präsenz des göttlichen Lichts in allem Geschaffenen.

53 Tatsächlich gibt es, wenn auch nicht prominent in Julians Zeit bezeugt, so doch an der Wende vom fünften zum sechsten Jahrhundert, in der es weiterhin eine ähnliche Konstellation etwa in der Frontstellung von christlichen Philosophen und der Proklos-Schule gab, auch Belege für ein Ergreifen der Sachgemeinsamkeiten in unpolemischer Erörterung, in der die Selbstverständlichkeit des geistigen Miteinanders gar nicht mehr thematisiert ist. So bei Dionysius Areopagita: "Everything happens as though the time of religious controversy and of polemics between Christian and non-Christian had passed, for the pseudo-Dionysius breathes no criticism of Platonic practise; indeed allusions to his non-Christian sources are non-existent" (McEvoy (Anm. 15), S. 170.). 
Von Philon abgesehen ist Kelsos der erste Platoniker, von dem nicht nur ein oder mehrere $\theta \varepsilon \circ \lambda \circ \gamma \circ \hat{v} \mu \varepsilon v \alpha$, sondern eine ganze, in sich geschlossene $\theta \varepsilon \circ \lambda \circ \gamma^{\prime} \alpha$ bezeugt sind. $\mathrm{Zu}$ einer solchen Leistung war zuvor keine griechische Philosophie, und seltsamerweise keine Mysterien-Religion gelangt. Aber es muß der Finger darauf gelegt werden, daß hier ein ,Modell` entstanden war, kurz bevor das Christentum zu analoger Leistung ansetzte - und dies Modell sollte in säkularer Diskussion ebenso zum Skandalon wie zum Vorbild werden: Eben als das Christentum es unternahm, seine Grundbegriffe spekulativ zu klären, fand es das Modell einer spekulativen Theologie vor, das der Platonismus unmittelbar zuvor erarbeitet hatte. Was diese Priorität des platonischen Modells, und was diese Duplizität der Ansätze, analog trotz vieler Gegensätzlichkeiten, für die Geistesgeschichte Europas bedeuten sollte, ist vermutlich noch nicht im entferntesten ausgeschöpft. ${ }^{54}$

\section{Julian gegen das Christentum: Grundtendenz und Einzelprobleme}

Doch gerade auf dem gemeinsamen Feld ergeben sich auch die Differenzen und Unvereinbarkeiten in einer Weise, wie sie klarer sonst nie oder nur selten in der Geschichte hervortreten: Sie sind es, die auf Seiten aller Beteiligten zu kernigen Aussagen führen wie der des Johannes Chrysostomus, ein christlicher Theologe könne Platon nicht zitieren, ohne seinen Herrn damit schwer zu lästern, ${ }^{55}$ oder Tertullians berühmte (nur vermeintlich) rhetorische Frage, ,was hat Athen mit Jerusalem, was die [Platonische] Akademie mit der Kirche zu tun?" (De praesriptione haereticorum 7) ${ }^{56}$; Plotin dagegen, der sich mit Gnostikern wie Valentinian und Basilides darin trifft, sich in sprachlich umkreisender Eingrenzung der absoluten Transzendenz des Ersten ständig und immer gewagter zu überbieten, ${ }^{57}$ polemisiert in für ihn ungewohnt scharfen Attacken gegen Gnostiker, ${ }^{58}$ vor allem dagegen, dass sie den Kosmos für zeitlich geschaffen halten (Enneade II.9.3,1-3 und 11f. sowie 16-21) - worin diese sich wiederum mit den Christen treffen, wenn auch andererseits nicht in dem, was Plotin als eigentliche Konsequenz befürchtet: dass damit nämlich der Kosmos als übel abgewertet wird; und Julian, selbst ein fleißiger Mythenerzähler, beginnt seine wohl berühmteste und grundlegendste Attacke gegen das Christentum mit der Feststellung, es enthalte zwar

54 Dörrie (Anm. 13), S. 48.

55 Johannes Chrysostomus, Adversus Judaeos 5 (PG 48, 886).

56 Freilich hat Kobusch, Christliche Philosophie (Anm. 20), S. 33, darauf die richtige Antwort gegeben, dass Alexandria recht genau und überzeugend zeige, was beide miteinander gemein und $\mathrm{zu}$ tun haben (von der Theologie in Antiochia könnte man mutatis mutandis Ähnliches behaupten).

57 Dazu Whittaker, John, Basilides on the Ineffability of God, in: The Harvard Theological Review 62 (1969), S. 367-371, hier S. 368, mit Belegzitaten.

58 "[T] $]$ his is the only treatise in the Enneads where Plotinus explicitly criticizes his contemporaries“, bemerkt O’Brien, Denis, Plotinus on Matter and Evil, in: The Cambridge Companion to Plotinus, Hg. Lloyd P. Gerson, Cambridge 1996, S. 171-195, hier 187. 
nichts wahrhaft Göttliches, doch habe es durch Manipulation des vernunftlosen Seelenteils, der sich gerne Geschichten erzählen lässt, seine fehlende Wahrheit mit monströsen Lügenmärchen über angeblich wirklich Geschehenes suppliert (Contra Galilaeos 39b). ${ }^{59}$

Die Schärfe solcher Aussagen zeugt vom Bewusstsein, dass gerade auf der eben skizzierten gemeinsamen Grundlage die Gefahr besteht, mit den Ähnlichkeiten und Übereinstimmungen in der Denkform zwangsläufig unannehmbare Inhalte ,einzukaufen“; auch zeigen solche Aussagen, pointiert wie sie sind, dass das vielleicht gerade half, die Gegensätze in den Inhalten klarer zu sehen und unmissverständlicher zu formulieren. Nicht umsonst ist es ein Zeitalter der doktrinalen Definitionskontroversen, nicht nur für das Christentum. Auch hierzu nur einiges, was als Belegbeispiel im Sinne von partes pro toto dienen soll: Vor nicht allzu langer Zeit hat Rémi Brague von der Gnostik als einer „Remythisierung“ des Platonismus gehandelt, ${ }^{60}$ und damit wohl tatsächlich bündig eine Art gut verwendbarer Beinahe-Definition der Gnostik gegeben. Der Schulplatonismus hat unter anderem gerade an der schlecht philosophisch undifferenzierten, narrativ polarisierenden Weltdeutung der Gnostiker Anstoß genommen. ${ }^{61}$ Seine Antwort darauf war keine Preisgabe des Mythischen, ${ }^{62}$ sondern dessen detaillierte und philosophisch unterscheidende Ausdeutung und Erklärung als bildhafte Darstellung einer immerwährenden Begründung für das Sein der Dinge - der inneren Welt des Menschen insbesondere - und der geistigen Erlösungsfähigkeit des Menschen. Diese Dinge, die der Mythos erzählt (und die Philosophie auseinandersetzt), sind nie passiert, doch geschehen sie immerfort, sagt der ,,platonische Katechismus“ des Salustios an berühmter Stelle (De dis et mundo IV 8ff.), und genauso sieht es Julian in seinem Hymnos an Magna Mater (10, 169d-170c): „Niemand soll vermeinen“, sagt er dort, „dass ich behaupte, all dies habe einmal stattgefunden und sei wirklich geschehen“, worauf eine engagierte Auslegung des vorgetragenen Mythos als Ausdruck des Immerwährenden, Unzeitlichen, in zeitlicher, geschichtlich-geschichtenhafter Erzählung folgt. Von solch unzeitlichen Quellen, die das Dunkel der Existenz in ungeschichtlichem Blick und eigener

59 Einen guten Überblick über die Anfänge dieser Kontroverse zwischen paganem Platonismus und christlich-platonischer Theologie bieten die Kapitel drei bis fünf von Berchman, Robert M., Porphyry against the Christians, Leiden/Boston 2005, insbesondere S. 17-117 und S. 222-226.

60 Vgl. Brague, Rémi, The Wisdom of the World, Chicago/London 2003, S. 63.

61 Siehe zu den paradigmatischen Streitpunkten zwischen Plotin als dem Archegeten des Neuplatonismus und seinen unspezifizierten gnostischen Gegnern Alt, Karin, Philosophie gegen Gnosis. Plotins Polemik in seiner Schrift II.9, Mainz/Stuttgart 1990, insbesondere S. 12-20, sowie Schäfer (Anm. 32), S. 170-192. Interessant ist Berchmans Hinweis darauf, dass die Christentumskritik bei Porphyrios und anderen den Duktus der Argumentation von Plotins GnostikerEnneade gewissermaßen nachgebaut haben könnte: Vgl. Berchman (Anm. 59), S. 93-117.

62 So zeigt es unter anderem auch die Übernahme und Imitation gnostischer Gedanken und Terminologie, wie sie sich bei Plutarch belegen lässt: Vgl. Betz, Hans Dieter, Observations on Some Gnostizising Passages in Plutarch, in: Ders., Hellenismus und Urchristentum (Anm. 45), S. 135146. 
Ausdrucksform erschließen, nährt sich der Platonismus Julians, ganz so, wie es ihm (spätestens) seit den Zeiten des Iamblichos vorgegeben ist: von theurgischen Einsichten (Hymnos an Magna Mater 12, 172d-173a), von magischen Erklärmodellen, und vor allem auch von Orakelsprüchen und -sammlungen, die für Julian nicht nur die Welterkenntnis erschließen können, sondern auch die Philosophie richtig auslegen helfen, etwa die des Aristoteles, aber auch sogar die Platons: „Weil ich denke, dass die aristotelischen Thesen allzu wenig ausreichen, solange sie nicht mit denen Platons, und vor allem denen der gottgegebenen Orakel, in Verbindung gebracht werden“", meint Julian entsprechend. ${ }^{63}$ Doch nicht nur dafür eigneten sich theurgische Theorien und magische Weltdeutung. Sie waren auch dazu angetan, das Christentum durch Überbietung zu widerlegen, etwa, indem man aus versierter Praxis versuchte, Wundern, Auferstehungen, Epiphanien und ähnlichem den Anspruch zu nehmen, christlicher Sonderbesitz oder ein geschichtlich einmaliger Wahrheitsbeleg zu sein, und sie als gängige Phänomene arkaner Beschwörungsmöglichkeiten allgemein zu erweisen. ${ }^{64}$ „Danach handelt es sich bei diesem Auferstehungsglauben keineswegs um ein einzigartiges oder neues Phänomen, sondern um längst Bekanntes.“65

Ein ähnliches Bild bietet die Kontroverse um die Kosmologie: Das Christentum beschwört in seinen entpersonalisierenden und streng verdinglichenden Auffassungen von den Himmelskörpern als bloßen funktional von Gott gesetzten „Leuchten“ am Himmelsdach (Genesis 1,14-18) eigentlich einen uralten Konflikt der griechischen Philosophie herauf, den der Platonismus mit dem Sieg der Lehre von der Göttlichkeit der Gestirne eigentlich schon gewonnen zu haben schien. ${ }^{66}$ Julians Invektive im Helios-Hymnos (148c) gegen solche, die der Göttlichkeit der supralunaren Welt mit Verweigerungshaltung begegnen und sie ohne geistig anagogen Gewinn nur „blöde anstieren“, ist wiederum auf die Tendenz der christlichen Denker gemünzt, das einmalige Geschichtliche zum Ort der Begegnung mit

63 Hymnos an Magna Mater 3, 162cd: Die Erläuterung und Ergänzung des Aristoteles durch Platon ist ja sozusagen das Credo des Porphyrios bei Julian. Zu den „Chaldäischen Orakeln“ und dem Theurgieglauben vgl. Smith, Rowland, Julian's Gods. Religion and Philosophy in the Thought and Action of Julian the Apostate, London 1995, S. 91-113. Dass mit den Orakeln bei Julian aber nicht nur die berüchtigten „Chaldäischen“ gemeint sind, zeigt etwa Julians Praxis der Übersendung von Orakelsammlungen aus Delphi an pagane Gemeinden zur geistigen Orientierung und die Empfehlung von Orakelsprüchen des Gottes von Didyma: Vgl. Brief 88 (451ab) und Brief 89b (297cd).

64 Einschlägig dazu etwa Betz, Hans Dieter, Zum Problem der Auferstehung Jesu im Lichte der griechischen magischen Papyri, in: Ders. (Anm. 45), S. 230-61.

65 Betz (Anm. 64), S. 235.

66 Platon gibt in Nomoi 966e-967e eine geraffte Darstellung dieser Kontroverse und legt die platonische Lehrmeinung dazu zugrunde: „Denn vor ihren Augen schien alles, was sich am Himmel bewegte, eine Masse von Steinen und Erde und von vielen andern unbeseelten Stoffen zu sein, die die Ursachen für das gesamte All lieferten. Das war es, was damals viele gottlose Überzeugungen hervorrief [...]. Jetzt aber, wie gesagt, verhält es sich genau umgekehrt“" $(967 \mathrm{~cd})$. 
Gott zu machen und das Ewige im Kosmos demgegenüber als bloßes Indiz für Gottes Größe in den Hintergrund treten zu lassen.

Die christliche Theologie hatte ihrerseits mit der gnostischen Remythisierung platonischer Denkart ihre eigenen Probleme, und die betrafen nun wiederum auch den Platonismus vom Gepräge der Anhänger Julians. Zwar teilten die christlichen Theologen durchaus den Abscheu des Schulplatonismus gegen den lauernden Manichäismus oder Zoroastismus in den gnostischen Ansichten ${ }^{67}$ und kämpften darin an der Seite der paganen Platoniker gegen eine befürchtete remythisierende Verballhornung des Platonismus und des ,echten Platon“ durch die verschiedensten gnostischen Denominationen ${ }^{68}$ - teilten wohl auch beider "Einsichtsanspruch“ (den Anspruch auf $\gamma v \hat{\omega} \sigma ı \varsigma$ also) für die eigenen Adepten und befanden sich damit in Opposition zu den jeweils anderen Strömungen. Ihren Anspruch, die wahre Vollendung des echten Platonismus zu sein (den die christliche Theologie in Konkurrenz mit der julianisch-platonischen und gnostischen Theologie vertrat), gründeten die christlichen Denker nun insbesondere darauf, keine Mythen zu erzählen, sondern Heilsgeschichte. Was sie zur Erlösung erzählten, war einmal geschehen und geschah nicht fortwährend. Es ist bezeichnend für das christliche Credo, das „sub Pontio Pilato“ und bezeichnend für das christliche Evangelium, eine normative „Fülle der Zeit“ geschichtlich benennen zu können. ${ }^{69}$ Das Sarkisch-Historische des orthodoxen Christentums ${ }^{70}$ spiegelt sich ebenfalls in der Ablehnung des auch die Geschichte remythisierenden gnostischen Grundgedankens, der sich in diesem Fall etwa in der Lehrvariante niederschlug, Christus sei nicht wahrhaft, sondern in einem ,ungeschichtlichen“, mythischen Scheinleib

67 Dass selbst diese aber dem Platonismus nicht unversöhnlich, das heißt in diesem Fall: ohne jede Möglichkeit interpretierend vereinnahmt zu werden, gegenüberstanden, zeigt gerade wieder Julian, dessen Mithras-Frömmigkeit sich in seine platonische Denkform anscheinend ohne größere Reibungsverluste einschmiegt. Vgl. dazu Smith (Anm. 63), S. 124ff.; Witt, R. E., Iamblichus as a forerunner of Julian, in: De Jamblique a Proclus, Hg. H. Dörrie, Vandoeuvres-Genève 1974, S. 35-64, sowie Turcan, Robert, Mithras Platonicus. Recherches sur l'Hellénisation philosophique de Mithra, Leiden 1975 (insbesondere das abschließende Kapitel „Julien II, Héliolatre“), aber auch die Rezension dazu von Dillon, John, The Platonizing of Mithra, in: Journal of Mithraic Studies 2 (1977), S. 79-85.

68 Plotin ist ein prominentes Beispiel für diesen Vorwurf an die Gnostiker: Vgl. Enneade II.9.6,1$62 ; 17,1 \mathrm{ff}$.

69 „Als Cyrinius Statthalter von Syrien war [...]“ und „,es war im fünfzehnten Jahr der Regierung des Kaisers Tiberius; Pontius Pilatus war Statthalter von Judäa, Herodes Tetrarch von Galiläa, sein Bruder Philippus Tetrarch von Ituräa und Trachonitis, Lysanias Tetrarch von Abilene; Hohepriester waren Hannas und Kajaphas [...]“, heißt es in den Evangelien. Den geschichtlichen Anspruch und die doktrinale Bedeutung dieses Anspruchs für das Selbstverständnis des Christentums zeigt Brague, Rémi, Geschichte und Christentum brauchen einander, in: Christ und Zeit. Festschrift für Hans Maier, Hg. H. O. Seitschek, München 2007, S. 21-33.

70 Auch Gnostiker konnten sich ja unter anderem als Christen empfinden, genauso, wie sie sich durchwegs als Platons Erben empfunden haben mögen, was prominent die gnostischen Richtungen der Valentinianer und der Ophiten zu belegen scheinen. Und auch Christen bezeichneten sich mitunter (in einem unspezifischeren Sinne von „wahrhaft Erkennenden“) als „Gnostiker“: Vgl. Clemens Alexandrinus, Stromata, VII $13,1$. 
gekreuzigt worden. ${ }^{71}$ Solche gnostischen Denominationen näherten sich damit wiederum der Denkart des paganen Platonismus an, der seinerseits unüberwindliche Probleme etwa mit der christlichen Reliquienverehrung hatte (wie deutlich Julians Auseinandersetzung mit den Antiochenern zeigt ${ }^{72}$ ), also ebenfalls mit einer Ausprägung des Sarkisch-Historischen im Christentum. Auch die frühen Invektiven philosophischer Christentumsgegner wie Porphyrios und Kelsos versuchten ja bereits unter anderem gezielt, christliches Glaubensgut wie Jungfrauengeburt und Auferstehung als „Mythen“ zu erweisen, das heißt als traditionsmotivisch erklärende Geschichten ohne historischen Anspruch, und initiierten damit eine lange und anhaltende Tradition der Christentumskritik. Die Positionen von Christen, Gnostikern und „letzten Heiden“ bildeten einander umkreisend, ausei-

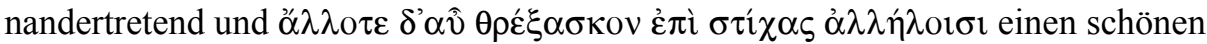
platonischen Reigen von Auseinanderstreben und Zusammenschluss.

Repräsentativ für das eben Gesagte steht die Aussage des Zweiten Petrus-

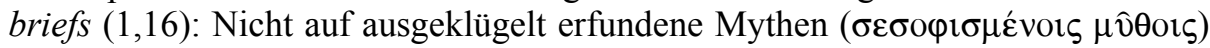
stütze sich das Christentum, sondern auf das Augenzeugnis eines geschichtlichen göttlichen Machterweises, also auf historische Tatsachenerfahrungen. Gegen diesen Gedanken der geschichtlichen Parusie der christlichen Auffassung protestiert Julian folgerichtig in seinem Helios-Hymnos, als würde er gezielt gegen den Johanneischen Logos-Hymnos anschreiben: Die Sonne ist das, was man zu allen Zeiten - also ungeschichtlich und keinesfalls einmalig - gesehen und zum normativen Ausrichtungspunkt (vgl. Politeia 508a-e) gemacht hat, Christus dagegen habe von den noch Lebenden keiner je gesehen - ein schwerwiegendes Problem

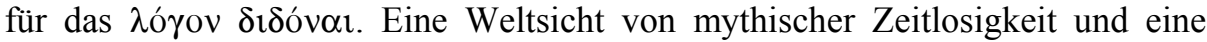
Philosophie des semper, ubique, ab omnibus wird hier der historischen Versicherung ,wir haben Seine Herrlichkeit gesehen“ (Joh 1,14) und der Theologie des ,in jener Zeit" wirksam entgegengesetzt.

Die beste Widerlegung des Christentums für die paganen Platoniker lag hier, im Fall des Mythischen, das „,besser“ ist als das einmalig Geschichtliche, das sich in dieser Sichtweise also keineswegs als qualitativ einmalig erweist, ebenso wie im Fall der magisch-theurgischen Expertise, die den Glaubensaussagen des Christentums ausgestellt wird, darin, das Gemeinsame zu demonstrieren und gerade darin als überlegen aufzutrumpfen. Das Christentum dagegen sah sich durch diese Strategie seiner Gegner gezwungen, seine begriffliche Basis und den Status seiner Aussagen zu klären und philosophisch weiter zu schärfen. - Und wurde damit ebenso philosophisch wie der Platonismus, der es bekämpfte, und mit Sicherheit letztendlich philosophisch ausgereifter als Julians Version desselben.

71 Wie die Valentinianer und Basilidianer - jeweils anders - meinten. Auch das ist mythisch gedacht: Aeneas in der Ilias, Helena in Ägypten etwa sind Beispiele (und wohl geistesgeschichtliche Vorlagen) der Errettung und Entrückung durch eine Gottheit und die göttliche Täuschung der Menschen durch einen Scheinleib in der antiken Mythologie: Vgl. Kerényi, Karl, Griechische Grundbegriffe, Zürich 1964, S. 29-38.

72 Vgl. Julian, Misopogon 361c, und García Blanco (Anm. 8), S. 48. 
5. Fazit: Beim Unterscheiden das Gemeinsame (be)achten

Alles in allem wird es auf dem damit skizzierten Hintergrund kaum wunder nehmen, dass Julian als wirksamste Waffe seines weltanschaulichen Kampfes ein Bildungsverbot gegen die Christen anstrengte, ihnen also den Anschluss an die gemeinsame als ,,antike“ verstandene Denkart, wie sie von allen Beteiligten als Definitionsform gesucht wurde, verunmöglichen wollte: Er entzog damit genau das gemeinsame Fundament der geistigen Epochenzugehörigkeit, das als Grundlage einen geistigen Austausch, aber auch die erbitterten geistigen Kontroversen erst möglich machte. Julian mag sich davon Folgen erhofft haben, wie sie im Jahr 529 die - offenbar unter ungleich realistischeren historischen Vorgaben erlassenen - Verbotsgesetze des Kaisers Justinian für den paganen Platonismus mit sich brachten. Dass es genau diese Maßnahme Julians war, die bei Freund und Feind größtes Entsetzen und Unverständnis hervorrief, erklärt sich daraus, dass sie eben gezielt dem ,synkretistischen“ Geist der allgemeinen, öffnenden Anerkennung auf gemeinsamer Grundlage der antikenverbundenen platonischen norma normans widersprach und die geistige Lebensgrundlage geradezu verweigerte. ${ }^{73}$ Entsprechend war auch nach Julians Tod die Auseinandersetzung seiner ehemaligen Gegner eine um das geistig formende Hoheitsgebiet der epochengestaltenden Bildung, die Julian als Schulbanknachbar des Basilius und des Gregor von Nazianz, und Origenes wie Plotin als Schüler des Ammonios Sakkas hervorgebracht hat (was, wenn nicht wahr, so doch überzeugend erfunden ist).

Ohne dass ich es hier detailliert ausführen wollte oder könnte, scheint mir bei all dem doch Folgendes erwähnenswert: Mit letzter Konsequenz zuende gedacht zeigt sich vielleicht ausgerechnet in diesem aufs Fundamentale abzielende Vorgehen Julians, dass sich der Platonismus somit als epochenprägende Denkform erweist, die sich wie nur wenige solche epochenformenden Denkweisen eben auch distanzierend $\mathrm{zu}$ sich selbst verhalten und die eigenen Voraussetzungen grundlegend befragen und bedenken kann, offenbar sogar bis an die Grenzen der Möglichkeit ihrer eigenen „Aufhebung“. Denn vielleicht mehr als jede andere Philosophie ist die platonische ihrer ganzen inneren Anlage nach das, was jede Philosophie eigentlich ausmacht, nämlich ein ,Diskurs über letzte Fragen, [... das heißt über] solche, die am Ende der normalen Diskurse offen bleiben und auf deren Nichtaufwerfen die konsensuelle Stabilität unserer normalen, persönlichen, sozialen und wissenschaftlichen Lebenspraxis beruht ““ ${ }^{74}$

Ich weiß nicht, ob man die Diagnose stellen darf oder sollte, dass sich diese Auseinandersetzung durch Entzug des antik normierten Bildungsanspruchs in der Grundlegung des Antikenbilds im humanistischen Paideia-Ideal neuerer Zeiten gewissermaßen wiederholt - oder ob es lediglich so ist, dass diese Interpretation

73 Vgl. García Blanco (Anm. 8), S. 46, mit entsprechenden Belegen.

74 Spaemann, Robert, Die kontroverse Natur der Philosophie, in: Ders.: Philosophische Essays, Stuttgart 1983, S. 104-129, hier 106. 
sie jetzt bloß wiederholt. Eine solche These führte jedenfalls zurück an den Beginn der vorliegenden Überlegungen über die Erfindung der Vorstellung von einer nachchristlichen „Spätantike“ und den Diskussionen um eine „Platonisierung“ oder „Gnostisierung“ des Christentums. Denn

unter den führenden Männern der Altertumswissenschaft am Ende des 19. Jh. bestand weitgehende Einigkeit darüber, daß die [...] urchristliche Literatur aus der griechischrömischen Literaturgeschichte auszugliedern sei [...]. Die Gründe für diese Übereinstimmung waren durchaus verschiedener und nicht immer wissenschaftlicher Art. ${ }^{75}$

Doch kann man sie ,gut julianisch“ in der Kristallisationsfigur der Wissenschaft (und der Wissenschaftsepoche) Ulrich von Wilamowitz-Moellendorffs gebündelt finden; der setzte das Ende der klassischen (und somit „wahren“) Antike „um das Jahr 300 v.Chr. an. Die nachklassische Periode ist dagegen nur eine Zeit des langsamen Erschlaffens und des Verfalls“. ${ }^{76}$ Dazu kommt: „Wie Mommsen stand auch sein Schwiegersohn Wilamowitz dem Christentum abweisend gegenüber. Er sah sich seit der Schulzeit in Schulpforta der ,religio Platonica' verpflichtet, die dem Christentum entgegengesetzt war"“. ${ }^{77}$ Es gehört wohl zum Gemeinsamen im Unterscheiden, dass man von Schulpforta aber auch die genau entgegengesetzte Ansicht Nietzsches mitnehmen konnte, dass Platonismus und Christentum in passgenauer Einigkeit an wirklich allem schuld seien, vor allem am Verlust der Antike für die kulturelle Entwicklung. Der Komplexität des Verhältnisses von Platonismus und Christentum zu Julians Zeiten werden aber beide Positionen nicht gerecht.

75 Betz, Hans Dieter, Neues Testament und griechisch-hellenistische Überlieferung, in: Ders. (Anm. 45), S. 262-269, hier 263.

76 Betz (Anm. 75), S. 266.

77 Betz (Anm. 75), S. 265. 